\title{
Effect of Sintering Temperature on Dosimetric Properties of BeO Ceramic Pellets Synthesized Using Precipitation Method
}

\author{
V.Altunal ${ }^{1}$, E.Bulur ${ }^{2}$ V.Guckan ${ }^{1}$, A.Özdemir ${ }^{1}$, A.Sotelo ${ }^{3}$, Z.Yeğingil ${ }^{1}$ \\ ${ }^{1}$ ÇukurovaUniversity, Physics Department, Balcalı, 01330 Sarıçam, Adana, Turkey \\ ${ }^{2}$ Middle East Technical University, Department of Physics, 06800 Ankara, Turkey \\ ${ }^{3}$ Instituto de Ciencia de Materiales de Aragón (CSIC-Universidad de Zaragoza), Ma de Luna, 3, 50018 Zaragoza, Spain
}

\section{Abstract}

$\mathrm{BeO}$ is a promising phosphor for radiation dosimetry due to fading, dose response and reproducibility of OSL-signal correspond well with requirements to clinical and personal dosimeters. In this study, BeO samples were prepared using precipitation method, pelletized and then sintered at temperatures 1200,1400 and $1600{ }^{\circ} \mathrm{C}$ to afford dried pellets with better crystallinity and luminescence characteristics. Test results of X-ray diffraction (XRD) and Scanning Electron Microscope (SEM) revealed that enhanced of luminescence properties with increase of sintering temperature is ascribed to the densification and the well-defined boundaries between the particles with sizes between $1-5 \mu \mathrm{m}$ at $1600{ }^{\circ} \mathrm{C}$. The effects of sintering temperature on the X-ray luminescence emission and on the luminescence properties were investigated. The X-ray emission spectra of $\mathrm{BeO}$ pellets sintered at various temperatures were obtained as a broad peak in the region $200-450 \mathrm{~nm}$ with the maximum around $250 \mathrm{~nm}$. The OSL signals were observed for the preheating temperatures from 50 up to $500{ }^{\circ} \mathrm{C}$. The highly light sensitive $\mathrm{TL}$ peaks of the bleached TL curve at around 170 and $275^{\circ} \mathrm{C} ; 275^{\circ} \mathrm{C}$; and $170{ }^{\circ} \mathrm{C}$ contribute to the OSL signals at the sintering temperatures 1200,1400 , and $1600{ }^{\circ} \mathrm{C}$, respectively. Characteristics of OSL efficiency with respect to readout temperature were analyzed. Thermal quenching energies were found as $0.61,0.55$ and $0.53 \mathrm{eV}$ using the OSL signals obtained at various readout temperatures ranging from $50^{\circ} \mathrm{C}$ to $110{ }^{\circ} \mathrm{C}$ and $0.57,0.54$ and $0.51 \mathrm{eV}$ for that of TOSL method, for the samples sintered at 1200,1400 and $1600{ }^{\circ} \mathrm{C}$, respectively. The dose response of the total OSL signals is nearly linear from 0.1 to $50 \mathrm{~Gy}$ for the sintering temperatures of 1200 and $1400{ }^{\circ} \mathrm{C}$, and perfectly linear for $1600{ }^{\circ} \mathrm{C}$ in the same dose region. After the $24 \mathrm{~h}$ in which the shallow traps are responsible from the observed fading of the material, the fading of the total OSL signals was found as $-3.1 \%$ and $-4.3 \%$ associated 
with the 1200 and $1400{ }^{\circ} \mathrm{C}$ sintering temperatures, respectively. There was no fading with respect to the first reading for the samples sintered at $1600^{\circ} \mathrm{C}$.

The present study may promote the application of $\mathrm{BeO}$ luminophore synthesized using precipitation technique and sintered at $1600^{\circ} \mathrm{C}$, in medical dosimetry.

\section{Introduction}

Beryllium Oxide $(\mathrm{BeO})$ has been widely used for numerous applications in different fields of technology since 1950s. Due to its unique features such as high heat conductivity (as high as that of aluminum), high electrical resistivity (> $1013 \Omega-\mathrm{cm})$, high chemical and thermal stability, hardness $\left(1250 \mathrm{~kg} / \mathrm{mm}^{2}\right)$, high melting point $\left(2570{ }^{\circ} \mathrm{C}\right)$, high transparency over wide spectral range (121-7000 nm), a wide energy gap (10.6 eV), a low thermal neutron cross-section (10 $\mathrm{mb}$ ), it is used as a material of heat sink, thermal shock resistance (refractory ware), high efficiency moderator and reflector in electronic and nuclear industry.

As well as the features mentioned above, since $\mathrm{BeO}$ is a tissue equivalent material $(Z=7.13)$, it has attracted the attention of many researchers in radiation dosimetry applications. The history of $\mathrm{BeO}$ begins with the study of the possibility of using visible photons, as stimulation source, to obtain the UV emission from a slurry of powdered $\mathrm{BeO}$ after the irradiation with X-ray (Albrecht and Mandeville, 1956). According to the study by Scarpa (1970), a commercial sintered BeO was considered as a very promising thermoluminescent material which may be worked in mixed fields of thermal neutrons and $y$-rays. The usage of OSL from disks and powder samples of $\mathrm{BeO}$ for radiation dosimetry was first suggested by Rhyner and Miller (1970).

Many reports related to luminescence characteristics of the commercial $\mathrm{BeO}$ chips (Thermalox 995) have been published using thermoluminescence (TL) in detail (Tochilin et al., 1969; Crase and Gammage, 1975; Gammage, 1977; Horowitz, 1984; McKeever, 1985; McKeever et al., 1995; Kiiko et al., 2001). It was announced that the glow curve of the commercial BeO ceramics has light sensitive TL peaks and it could be a problem for TL dosimetry applications.

After the properties of BeO chips (Thermalox 995) using OSL were firstly reported in detail by Bulur and Goksu (1998), considerable interest has centered on the material for OSL dosimetry. 
Sommer and Henniger (2006); Sommer et al. (2007); Sommer et al. (2008) developed an OSL dosimetry system based on the outstanding optical properties of $\mathrm{BeO}$ Thermalox 995. Meanwhile, Bulur (2007) investigated TL properties and photo-transferred luminescence signals of this material. BeO was also studied using LM-OSL technique by Bulur and Yeltik (2010). At the same time, Watanabe et al. (2010) investigated TL, OSL and ESR properties in irradiated Thermalox 995. Yukihara (2011) has reported a study on the same material related with the time-resolved OSL (TR-OSL). A further study of TR-OSL signals was achieved by Bulur and Saraç (2013); Bulur (2014). Recently, Yukihara et al. (2016) have reported a protocol for new users studying $\mathrm{BeO}$ for different purposes in radiation dosimetry using an automated research OSL readers.

On the other hand, the thermoluminescence properties of synthesized BeO in ceramic and polycrystalline powder forms were investigated by various authors. Yamashita et al. (1974) synthesized BeO doped with ( $\mathrm{Li}, \mathrm{Na}, \mathrm{Si}, \mathrm{Ge}, \mathrm{B}$, and Al) for TLD using Solid State Synthesis Method sintered at $1500{ }^{\circ} \mathrm{C}$. The dose and energy response, emission spectrums and TL fading properties of $\mathrm{BeO}$ doped with $\mathrm{Li}$ or $\mathrm{Na}$ were reported to be acceptable. TL and ESR characteristics of two types BeO transparent ceramics were studied by Kortov et al. (1993) using 1200 and $1600{ }^{\circ} \mathrm{C}$ sintering temperatures. They reported that the optically transparent high-density $\mathrm{BeO}$ ceramics, simultaneously doped with $\mathrm{Li}$ and $\mathrm{Nd}$ gave the best results. Additionally, TL properties were studied both by Ogorodnikov et al. (1996) for BeO single crystals doped with B or $\mathrm{Li}$ impurities in different concentrations and by Kortov and Milman (1996) for the transparent BeO doped with Li. Transparent BeO ceramics doped with a number of impurities, which were prepared by hot pressing at a temperature not higher than $1250{ }^{\circ} \mathrm{C}$ and a pressure of $30 \mathrm{MPa}$, were offered for ionizing radiation dosimetry as an alternative dosimetric material by Kiiko (2004). He also suggested it for being used in laser technology as material for fabrication of dielectric resonant tubes, waveguides, and dielectric non-transmitting mirrors. Recently, Wang et al. (2010) synthesized BeO nanoparticles using polyacrylamide gel route and determined the most appropriate sintering temperature as $1600{ }^{\circ} \mathrm{C}$. Zahedifar et al. (2011) studied the usability of nanomaterial BeO doped with $\mathrm{Mg}$ synthesized with sol-gel method, for TL dosimetry.

In this study, we synthesized the $\mathrm{BeO}$ polycrystalline powder material using precipitation method and used cold molding to shape it in pellets. All the pellets employed in luminescence measurements were sintered at 1200,1400 and $1600{ }^{\circ} \mathrm{C}$, for $4 \mathrm{~h}$ for comparison studies. 
Structural, morphological and luminescent properties were investigated. The first objective of this work is to take advantage of the gain in OSL efficiency that is to be expected from the use of high $\left(1600^{\circ} \mathrm{C}\right)$ sintering temperature. Other objective is to determine whether the variety of sintering temperatures will permit the preparation of samples with such specialized properties as high sensitivity to beta particles, linear dose response for exposures of a wide dose range, good consistency of repeated exposures and slow decay of stored energy at room temperature.

\section{Material and Method}

\subsection{Synthesis of BeO}

$\mathrm{BeO}$ powders were synthesized using precipitation synthesis route. In this method, polyethyleneimine solution (Sigma-Aldrich, analytical standard, $50 \%\left(\mathrm{~W} / \mathrm{V}\right.$ ) in $\mathrm{H}_{2} \mathrm{O}$ ) for polymerization and ammonium hydroxide solution $\left(\mathrm{NH}_{4} \mathrm{OH}\right.$ ) (Sigma-Aldrich, ACS reagent, 28.0$30.0 \% \mathrm{NH3}$ basis) as an initiator of the precipitate were used. As the precursor reactant, beryllium sulfate tetra-hydrate $\left(\mathrm{BeSO}_{4} \cdot 4 \mathrm{H}_{2} \mathrm{O}\right)($ Aldrich, $99.99 \%$ trace metals basis) was used. $\mathrm{A}$ general experimental procedure of this method is as follows.

Firstly, beryllium sulfate was mixed with distilled water using magnetic stirrer and waited until it completely dissolved. On the other hand, a certain amount of polyethyleneimine solution was dissolved in distilled water by stirring until it becomes completely transparent and was added to beryllium sulfate solution under vigorous stirring. Afterwards, a sufficient amount of ammonia was slowly added to the mixed solution by controlling $\mathrm{pH}$ until a white precipitate formation was observed. The precipitate was dried on the heater. In order to burn formed organics and obtain BeO powder, the dried sample was calcinated, using an ash furnace (Nabartherm, model P330), at $800{ }^{\circ} \mathrm{C}$ with $5{ }^{\circ} \mathrm{C} / \mathrm{min}$ heating rate for 4 hours in an oxygen atmosphere. A problem for $\mathrm{BeO}$ dosimeters is that they are toxic in powder form and cause severe lung diseases when inhaled. However, in ceramic disc form, BeO is harmless for human health. In this work, $\mathrm{BeO}$ samples were studied in pellet forms for easy handling and having more settled OSL signals. After the appropriate amount of material and pressure were determined through various measurements, $\mathrm{BeO}$ pellets were prepared in form of disks with $6.15 \mathrm{~mm}$ in diameter and $0.82 \mathrm{~mm}$ in thickness, 
using a cold hydraulic press (Carver, model 3853-9) with evacuable pellet dies of various sizes. In order to impart strength and integrity, prepared pellets were sintered, using a box furnace (Thermoscientific, model Lindberg/Blue $M^{T M}$ ), at three different temperatures (1200, 1400 and $1600^{\circ} \mathrm{C}$, for $4 \mathrm{~h}$ ) in an oxygen atmosphere. After these sintering processes, the shrinkage led to $\mathrm{BeO}$ disks with 5.86, 5.71, and $5.03 \mathrm{~mm}$ diameter and $0.67,0.66$ and $0.54 \mathrm{~mm}$ thickness, respectively.

\subsection{Characterization techniques}

Structural characterizations and surface morphologies of $\mathrm{BeO}$ pellet samples were investigated using X-ray Diffraction (XRD) and Scanning Electronic Microscopy (SEM) methods. X-ray diffraction measurements were carried out using a PANalytical EMPYREAN XRD with a copper (Cu) and cobalt (Co) X-ray tube (45 kV and $40 \mathrm{~mA}$ ), and $\mathrm{Cu}$ Ka radiation wavelength was $0.1541 \mathrm{~nm}$. XRD data were obtained using $0.0130^{\circ}(2 \mathrm{~h})$ step sizes and $0.9 \mathrm{~s}$ step from 10 to $90^{\circ}(2 \mathrm{~h})$. The identification of phases was determined using the International Center for Diffraction Data (ICDD) PDF 98-016-3468. The nanoscale microstructures of BeO pellets were examined using a FEI Quanta 650 field-emission Scanning Electron Microscope (SEM) with 30$100 \mathrm{kV}$ accelerating voltage and $100 \mathrm{nA}$ probe current. The X-ray luminescence $(\mathrm{XL})$ spectra of $\mathrm{BeO}$ pellets were obtained from a homemade $X$-ray luminescence system equipped with Ocean Optics branded QE Pro-model high-sensitivity spectrometer for low light level applications. In XL measurements, $f / 2$ collimator was used in front of fiber optic cable throughout the CCD detector while irradiating samples by mini X-ray tube operated at from $4 \mathrm{kV}$ up to $40 \mathrm{kV}$ for stimulating the phosphors.

\subsection{TL and OSL measurements}

OSL and TL measurements were carried out using Risø, DA-20 model TL/OSL reader system with a bialkali photomultiplier tube (Electron Tubes $9235 \mathrm{QA}$ ) and Blue LEDs ( $p \sim 470 \mathrm{~nm}$, FWHM $\sim 30 \mathrm{~nm}$ ) for stimulation. Irradiations were performed using an internal ${ }^{90} \mathrm{Sr} /{ }^{90} \mathrm{Y}$ beta irradiator of the Risø TL/OSL reader. The radiation source emits beta particles with a maximum 
energy of $2.27 \mathrm{MeV}$ and dose rate is approximately $6.689 \mathrm{~Gy} / \mathrm{min}$. Continuous wave (CW) stimulation was used as OSL stimulation mode at a power density of $\sim 50 \mathrm{mWcm}^{-2}$. Luminescence signals were recorded using a $7.5 \mathrm{~mm}$ thick UV band pass filter (Hoya, U-340, transmittance range from 250 to $390 \mathrm{~nm}$, $\max 340 \mathrm{~nm}$ ) located in front of the PMT. Thermoluminescence measurements were performed heating the sample from room temperature to $650{ }^{\circ} \mathrm{C}$ with heating rate of $2^{\circ} \mathrm{C} / \mathrm{s}$ in nitrogen atmosphere.

\section{Results and Discussions}

\subsection{Characterization of BeO}

After sintering BeO pellets at three different temperatures (1200, 1400 and $1600{ }^{\circ} \mathrm{C}$, for $4 \mathrm{~h}$ ), XRD analysis of the $\mathrm{BeO}$ pellets were performed to investigate the role of the sintering temperature on crystal structure of $\mathrm{BeO}$. Figure 1 shows the phase identification of $\mathrm{BeO}$ pellets sintered for 4 hours, as a function of sintering temperature, using the XRD pattern. Analysis of the XRD data showed that all of the reflections are assigned to BeO phase with hexagonal structure. The patterns of BeO pellet samples match very well with (ICDD) PDF card no 98-0163468. By the comparison of the characteristic XRD patterns, it was found that the crystallinity of the sintered $\mathrm{BeO}$ pellets was clearly improved with increasing sintering temperature. Additionally, the sharpened diffraction peaks show that the intensity of diffraction increased with increasing sintering temperature, which means that the BeO grains have grown and the size of the crystallites is very fine. Regarding the grain sizes of the synthesized BeO pellets, it was clarified that there is a positive effect of higher sintering temperature on OSL measurements which will be discussed in the Section 3.2.

The morphology of BeO pellets sintered at 1200,1400 and $1600{ }^{\circ} \mathrm{C}$ was investigated through SEM to figure out the particles shapes and sizes. It is clear that different sintering temperatures would create differences in the surface morphology of BeO. Sintering can be defined as the phenomenon of heat transfer to material which leads to the reduction of the specific surface area of a powder material in porous structure. Through this way it causes the growth of the particle contact points, thereby causing the pore shape to change and the pore volume to 
shrink. Sintering briefly begins with forming of a neck between particles contacting each other. Figure 2 shows SEM images of $\mathrm{BeO}$ pellets at various sintering temperatures. As it is seen in the images, it can be concluded that $\mathrm{BeO}$ particles sintered at $1200{ }^{\circ} \mathrm{C}$ just began to form necks and still maintain the porous structure at this temperature (see Fig. 2a). When the sintering temperature was $1400{ }^{\circ} \mathrm{C}$, besides the existence of the porous structure, the distribution of local neck-forming structures is increased inside the material (see Fig. 2b). With the sintering process at $1600{ }^{\circ} \mathrm{C}, \mathrm{BeO}$ is formed as a well crystalline material and $\mathrm{BeO}$ particles appeared to be as smoother, and bonded, producing a nonporous structure (see Fig. 2c).

As it is also seen in the SEM images (see Fig. 2a, 2b and 2c), regularly formed repeated particle shapes and their narrow size distribution were observed in the samples. While the grain sizes were detected as between $30-110 \mathrm{~nm}$ for BeO pellets sintered at $1200^{\circ} \mathrm{C}$, for that of $1400{ }^{\circ} \mathrm{C}$ it changed in some regions of the crystalline surface. On the other hand, the grain size detected for $\mathrm{BeO}$ pellet sintered at $1600{ }^{\circ} \mathrm{C}$ is between 1- $5 \mu \mathrm{m}$ (data not shown). It was clearly understood that the grains of $\mathrm{BeO}$ samples were grown with increasing sintering temperature. Furthermore, these results are consistent with literature. Wang et al. (2011) reported that the increase in the average grain size of the studied $\mathrm{BeO}$ material was associated with the increasing temperature of the experiment.

On the other hand, the decreasing size of the $\mathrm{BeO}$ pellets themselves presented in Section 2.1, with increasing sintering temperature is due to the dimensional (or volumetric) shrinkage which causes the density increase in the molded powders (or pellets) by sintering.

\subsection{TL and OSL signals}

In this work, we investigated the TL/OSL luminescence signals obtained from $\mathrm{BeO}$ pellets irradiated with $0.1 \mathrm{~Gy}$ beta dose. We began TL and OSL measurements by preheating $\mathrm{BeO}$ pellets at $110{ }^{\circ} \mathrm{C}$ for $60 \mathrm{~s}$ to eliminate unstable signals originated from shallow traps. Figures $3 a, 3 b, 3 c$ shows OSL signals of samples sintered at 1200,1400 and $1600{ }^{\circ} \mathrm{C}$, during blue light stimulation for $200 \mathrm{~s}$ at room temperature. As it is seen in the figures, all measured OSL decay curves were fitted to the resultant of three decaying functions of time using linear integration. In a previous study, it was defined for general order kinetic features of phosphorescence decay 
by Chen and McKeever, (1997). This fitting technique was also used for prompt isothermal decay curves of $\mathrm{MgB}_{4} \mathrm{O}_{7}$ :Dy, $\mathrm{Na}$ by Kitis et al., (2016). The model equation for these fittings can be written as

$y=S_{0}(b k g)+S_{1}+S_{2}+S_{3}$

$I(t)=b k g+I_{1}\left[1+\left(b_{1}-1\right) \frac{t}{\tau_{1}}\right]^{-\frac{b_{1}}{b_{1}-1}}+I_{2}\left[1+\left(b_{2}-1\right) \frac{t}{\tau_{2}}\right]^{-\frac{b_{2}}{b_{2}-1}}+I_{3}\left[1+\left(b_{3}-1\right) \frac{t}{\tau_{3}}\right]^{-\frac{b_{3}}{b_{3}-1}}$

where $S_{1}, S_{2}$ and $S_{3}$ are the general-order decay functions presenting the fast, the medium and the slow decay components of the OSL signal, respectively; $b \mathrm{~kg}$ represents a background value of the signal; $t$ is the stimulation time; $I(t)$ is the intensity of the OSL signals as a function of time; $I_{1,2,3}, \tau_{1,2,3}$ and $b_{1,2,3}$ are the amplitudes, the decay times and kinetic orders of the individual components, respectively. From the curve fitting, $I_{1,2,3}$ amplitudes, $\tau_{1,2,3}$ decay times and $b_{1,2,3}$ kinetic orders were determined and presented in Table 1 for each BeO pellet, respectively. Additionally, the perfection of fitting curves was tested using the figure of merit (FOM) (Balian and Eddy, 1977), and FOM values were found as around $1 \%$. It should be noted that the curve fitting using three decay functions is an approximation showing mathematical consistency rather than a proof of the existence of separate physical mechanisms (traps), and hence more detailed studies on this are evidently necessary.

Figure 3 shows the OSL signal intensities of the $\mathrm{BeO}$ pellets increase with the increasing sintering temperature. It demonstrates that the better crystal structure and morphology may affect the OSL signals positively and the material becomes optically superior with increasing particle size.

On the other hand, typical TL glow curves and the effect of OSL measurements ( $200 \mathrm{~s}$ OSL stimulation with blue LEDs) on TL glow curves of the BeO pellets were also investigated. In this work, all TL glow curves were recorded heating the samples from room temperature up to 650 ${ }^{\circ} \mathrm{C}$ at a heating rate of $2^{\circ} \mathrm{C} / \mathrm{s}$, after being irradiated with $0.1 \mathrm{~Gy}$ beta dose. Figure 4 shows TL and TL after OSL curves (residual TL) of BeO pellets.

As it is seen in Figure $4 \mathrm{a}$, the $\mathrm{TL}$ glow curve of a BeO pellet (sintered at $1200^{\circ} \mathrm{C}$ ) showed three peaks located at 170,275 and $395^{\circ} \mathrm{C}$. In TL glow curve obtained after blue light stimulation, the first and second peaks are affected, whereas the third peak is not affected by the light exposure. In order to investigate whether this result suggests the source of the OSL signal 
might be associated with the 170 and $275{ }^{\circ} \mathrm{C}$ TL peaks or not, preheating study (thermal stability) experiment was performed in the temperature range from 50 to $500{ }^{\circ} \mathrm{C}$ with $5{ }^{\circ} \mathrm{C}$ increments. For this purpose, the samples repeatedly heated to a preheat temperature after irradiation with $0.1 \mathrm{~Gy}$, and the remaining OSL signals were measured each time. Following the OSL measurements, the samples were deleted using TL measurements (up to $650{ }^{\circ} \mathrm{C}$ ). Changing intensity of OSL signals against the preheating temperatures was illustrated together with the bleached TL glow curve (obtained subtracting residual TL glow curve from TL glow curve) in the inset Figure 4a. In this figure, the OSL signals were observed very stable up to $120^{\circ} \mathrm{C}$ and started to decrease after this temperature. The OSL signal decrease correlates with the emptying of the $170^{\circ} \mathrm{C}$ TL peak after the OSL stimulation. After the complete discharging of the TL traps responsible for the $275^{\circ} \mathrm{C}$ TL peak, the OSL signals reach the zero level. It shows that the source of the OSL signals is associated with both the $170^{\circ} \mathrm{C}$ and $275^{\circ} \mathrm{C}$ bleached TL peaks and the OSL employs the same recombination centers as the $170{ }^{\circ} \mathrm{C}$ and $275{ }^{\circ} \mathrm{C}$ bleached TL peaks.

The TL glow curve of a $\mathrm{BeO}$ pellet sintered at $1400{ }^{\circ} \mathrm{C}$ showed three peaks located at $175^{\circ} \mathrm{C}$, $275^{\circ} \mathrm{C}$ and $475^{\circ} \mathrm{C}$ (see Fig. 4b). In the TL glow curve obtained after optical stimulation of 200 $\mathrm{s}$, the first and second peaks were affected, but the third peak not affected by light exposure. In order to investigate the correlation between the source of the OSL signals and $175{ }^{\circ} \mathrm{C}$ and $275^{\circ} \mathrm{C}$ peaks of the bleached TL glow curve, the preheating experiment described above were carried out. The intensities of OSL signals against the preheating temperatures were illustrated together with the bleached TL glow curve in the inset Figure 4b. Unlike the sample sintered at $1200{ }^{\circ} \mathrm{C}$, the preheating studies for the samples sintered at $1400{ }^{\circ} \mathrm{C}$, showed that after the complete discharging of the traps responsible for the $175{ }^{\circ} \mathrm{C}$ TL peak, the OSL signals had almost the same values during this process. The OSL signal was observed very stable and started to decrease only after preheating at $250^{\circ} \mathrm{C}$. Additionally, after the complete discharging of the TL traps responsible for the $275{ }^{\circ} \mathrm{C}$ TL peak, the OSL signals reached almost the zero level. This suggests that the origin of the OSL signals might be associated with only the $275^{\circ} \mathrm{C}$ TL peak. It is not clear whether the OSL and TL signals occurred from the same trap or not. But, it is also possible that the $275^{\circ} \mathrm{C}$ TL peak is not due to a single trap distribution but an integration of overlapping traps. On the other hand, it is possible to say that even if the $175^{\circ} \mathrm{C}$ TL peak has high light sensitivity, it did not contribute to the OSL signals and the optically extracted charges from the $175{ }^{\circ} \mathrm{C}$ trap may make some non-radiative transitions or the 
luminescence emission may not be at the transmittance range of the detection filter (340 \pm 40 nm). Similar results for the commercial BeO chips were reported by Bulur and Goksu (1998).

Figure $4 \mathrm{c}$ shows that a TL glow curve (in logarithmic scale) of a BeO pellet sintered at $1600{ }^{\circ} \mathrm{C}$ reveals four peaks located at $170{ }^{\circ} \mathrm{C}, \sim 350^{\circ} \mathrm{C}, \sim 490{ }^{\circ} \mathrm{C}$ and $\sim 560^{\circ} \mathrm{C}$ in the $\mathrm{TL}$ glow curve. After the OSL stimulation, the first peak located at $170{ }^{\circ} \mathrm{C}$ was affected from the OSL measurement (see Fig. 4c). Hence, the origin of the OSL signals can be associated with the 170 ${ }^{\circ} \mathrm{C}$ TL peak. In order to investigate whether this peak is responsible from OSL or not, preheating measurements were also carried out and intensities of OSL signals against the preheating temperatures were depicted together with the bleached TL glow curve for this sample in the inset of Figure 4c. It can be seen in the figure that the decrease in OSL signals starts around $120^{\circ} \mathrm{C}$ and ends around $200{ }^{\circ} \mathrm{C}$. It shows that the source of the OSL signal is indeed associated with the $170{ }^{\circ} \mathrm{C}$ TL peak, and the OSL signals occur from the same recombination centers with the $170^{\circ} \mathrm{C}$ TL peak.

\subsection{X-ray luminescence spectra of BeO}

The dominant luminescence in $\mathrm{BeO}$ is caused by the radiative annihilation of self-trapped excitons. When the temperature is higher than room temperature, luminescence is characterized by the $4.9 \mathrm{eV}$ emission band with full width half maximum $>1 \mathrm{eV}$. It is obvious that this emission band is placed far from the spectral range of maximum sensitivity of conventional photomultiplier tubes (PMT). On the other hand, it is known that the F-type centers in $\mathrm{BeO}$ show bright luminescence at 3-4 eV, so the observed luminescence spectrum is an integration of these two emission bands (3-4 eV \& $4.9 \mathrm{eV}$ ) (Ogorodnikov and Kruzhalov, 1997). Figure 5 shows the X-ray luminescence spectra of BeO pellets sintered at three different temperatures, 1200,1400 and $1600{ }^{\circ} \mathrm{C}$, with a resolution of $1 \mathrm{~nm}$ at room temperature. The $\mathrm{XL}$ spectrum of each sample has the same broad peak located between 200 and $450 \mathrm{~nm}$ with peak maximum at $250 \mathrm{~nm}$ (between 6.2 and $2.7 \mathrm{eV}$ ). The obtained emission is at transmittance range of Hoya U-340 filter which was used in all OSL and TL measurements in this study. However, even the used transmittance range was very convenient, the 3-4 eV emission band was recorded but the $4.9 \mathrm{eV}$ band was not, because it is located at the upper limit of spectral sensitivity (Hoya U-340 filter). It should be noted that OSL counts obtained during the 
measurements are relative i.e. "uncorrected OSL counts" and more detailed studies related with the measurability of the entire luminescence band of $\mathrm{BeO}$ are necessary in this field.

\subsection{Effect of Reading Temperature}

Temperature dependence of an OSL signal is one of the most important sources providing the required information for understanding the luminescence mechanism of the material. In many materials, including $\mathrm{BeO}$, a reduction in luminescence efficiency with temperatures higher than room temperature is observed and is called as thermal quenching which increases the probability of non-radiative decays of the luminescence centers from the excited to the ground states (Bøtter-Jensen et al., 2003). The temperature dependence of the OSL signal can be expressed by a function of the type

$I_{O S L}(T)=\eta(T) I_{O S L}=\frac{I_{O S L}}{1+\operatorname{Cexp}\left(-E_{Q} / k T\right)}$

where $I_{O S L}$ is OSL signal, $\eta(T)$ is luminescence efficiency as a function of temperature; $C$ is a constant, $E_{Q}$ is the thermal activation energy for the non-radiative process; $k$ is the Boltzmann constant and $\mathrm{T}$ is the absolute temperature (Bøtter-Jensen et al., 2003). In order to investigate the presence of thermal quenching, the effect of readout temperature on the OSL signal intensity was checked. After the irradiation of the $\mathrm{BeO}$ pellets with $0.1 \mathrm{~Gy}$ beta dose following the sintering procedures at 1200,1400 and $1600^{\circ} \mathrm{C}$, OSL signals were recorded with $200 \mathrm{~s}$ blue light stimulation at various readout temperatures from $50{ }^{\circ} \mathrm{C}$ to $110^{\circ} \mathrm{C}$ with $5^{\circ} \mathrm{C}$ increments. After each reading, the samples were deleted by $\mathrm{TL}$ readout up to $650^{\circ} \mathrm{C}$ and the samples were irradiated again with the same dose (see Fig. 6). It can be clearly seen from the Figure 6 that the decrease of OSL signal intensity with increasing readout temperature implies a considerable amount of thermal quenching. The luminescence outputs obtained at $110^{\circ} \mathrm{C}$ were reduced to nearly $20 \%$ of the level obtained at $50^{\circ} \mathrm{C}$ for the samples sintered at 1200,1400 and $1600{ }^{\circ} \mathrm{C}$. A similar thermal quenching effect is also predicted by Bulur and Goksu (1998) using the OSL measurements for Thermalox 995 to describe the effect of reading temperatures on OSL. 
Another method to determine the thermal quenching effect caused by increasing readout temperature is to subtract the TL curve from the curve obtained with OSL stimulation (the socalled TOSL curve). Here we obtained the TOSL curves for BeO pellets sintered at 1200, 1400 and $1600{ }^{\circ} \mathrm{C}$. We performed $0.1 \mathrm{~s}$ pulsed stimulation with $0.9 \mathrm{~s}$ time interval between the pulses. For each case with and without stimulation, the TL glow curves were obtained heating the samples to $425^{\circ} \mathrm{C}$ at a heating rate of $3{ }^{\circ} \mathrm{C} / \mathrm{s}$. In Figure 7a, 7b and 7c, the TOSL curves from BeO samples sintered at 1200,1400 and $1600{ }^{\circ} \mathrm{C}$ were given together with both the TL curves and TL curves obtained with OSL stimulation.

Thermal efficiency curves were given by plotting the natural logarithms of the OSL intensities, which were obtained at various readout temperatures (see Fig. 6), versus to the reciprocal of the readout temperatures in the inset Figures 7a, 7b and 7c, for each sintering temperature. Similarly, the natural logarithms of OSL intensities obtained from the initial parts of the TOSL curves as being plotted against $1 / T$ are given in the inset Figures $7 a, 7 b$ and $7 c$, for each sintering temperature. Fitting the obtained data to the Equation 2 , the quenching energies $\left(E_{Q}\right)$ were found as $0.61,0.55$ and $0.53 \mathrm{eV}$ for the samples sintered at 1200,1400 and $1600{ }^{\circ} \mathrm{C}$, respectively. On the other hand, when the method of TOSL was used, the quenching energies $\left(E_{Q}\right)$ were determined as $0.57,0.54$ and $0.51 \mathrm{eV}$, for the samples sintered at the above temperatures, respectively (see Table 2 ).

\subsection{Dose response curve of BeO}

Dose-response behavior due to the OSL signals from the BeO pellets sintered at 1200, 1400 and $1600{ }^{\circ} \mathrm{C}$, were investigated in the beta dose range between $0.1 \mathrm{~Gy}$ and $50 \mathrm{~Gy}$. The exposure doses to the material were $0.1,0.2,0.5,1,2,5,10,20$ and $50 \mathrm{~Gy}$. The OSL signals were obtained from the three $\mathrm{BeO}$ pellets for each dose value by a $200 \mathrm{~s}$ blue light stimulation at room temperature after preheating the samples at $110{ }^{\circ} \mathrm{C}$ for $60 \mathrm{~s}$ to eliminate the unstable signals.

The plots of linearly fitted curves for the normalized integrated OSL signals as a function of the radiation doses were given in Figures 8 for $\mathrm{BeO}$ pellets sintered at different temperatures. For each material the superlinearity indices were calculated using the Equation 
$g(D)=\left[D S^{\prime \prime}(D) / D S^{\prime}(D)\right]+1$

3

to determine the dose characteristics in the given range. In Equation 3, $D$ is the absorbed dose; $S^{\prime}(D)$ is the derivative of dose dependence function at a point $D$ and $S^{\prime \prime}(D)$ is the derivative at a certain point. Chen and McKeever proposed the function $g(D)$ as the "superlinearity index" (1994). An increasing dose dependence $\left(S^{\prime}(D)>0\right)$ indicates superlinearity if $g(D)>1$ $\left(S^{\prime \prime}(D)>0\right)$. Furthermore, $g(D)=1$ means a range of linearity and $g(D)<1$ signifies sublinearity. As a result, using linear fitting and Equation 3, $g(D)$ values were calculated as $0.992,0.983$ and 1.006 for the BeO pellets sintered at 1200,1400 and $1600{ }^{\circ} \mathrm{C}$, respectively. The $g(D)$ function was evaluated using 1000 fitting data as having perfectly the same values for each sintering temperature in the dose range from 0.1 to $50 \mathrm{~Gy}$. As it was evaluated from the obtained superlinearity indices $(g(D))$ dose response of this material sintered at different temperatures can be accepted as nearly linear for the sintering temperatures of 1200 and 1400 ${ }^{\circ} \mathrm{C}$, and linear for the sintering temperature of $1600^{\circ} \mathrm{C}$.

In the present experimental conditions and for the present BeO pellets sintered at 1200,1400 and $1600^{\circ} \mathrm{C}$, the minimum detectable dose (MDD) of each group of BeO pellets was estimated as a dose value based on three times the experimental standard deviation of the background signal from the unirradiated sample and on the luminescence sensitivity of the sample irradiated with a minimum applicable dose of the readout system. The MDD values were evaluated as 222,146 and $8 \mu \mathrm{Gy}$ for $\mathrm{BeO}$ pellets sintered at 1200,1400 and $1600{ }^{\circ} \mathrm{C}$, respectively. It should be noted that, these MDD values are considered only as an estimated order of magnitude, because we do not perform sufficient measurements in the low dose range due to being the radiation source not precisely calibrated.

\subsection{Reusability properties of BeO}

The OSL measurements must be reusable for the dosimetric applications, i.e., the OSL signals must give the same response, when it is re-measured under the same experimental procedures. In order to investigate the reusability, the signals were obtained from the three annealed $\mathrm{BeO}$ pellets exposed to $0.2 \mathrm{~Gy}$ beta dose by a $200 \mathrm{~s}$ blue light stimulation at room temperature. The same type of measurements was repeated 10 times. For each readout procedure the samples were firstly pre-heated to $110{ }^{\circ} \mathrm{C}$ for $60 \mathrm{~s}$ to eliminate unstable signals. In Figure 9, the 
normalized integrated OSL signals were plotted versus to the number of the experimental cycles for the samples sintered at 1200,1400 and $1600^{\circ} \mathrm{C}$. OSL signals indicated very good reusability over 10 cycles. The maximum deviation of the each integrated OSL output from that of the first readout was determined as 3.1\%, $4.3 \%$ and $1.5 \%$ for the BeO pellets sintered at 1200,1400 and $1600^{\circ} \mathrm{C}$, respectively.

\subsection{Short time dark storage fading}

Luminescence signals of reliable dosimetric materials are expected not to fade upon storage after exposure. In order to investigate the fading characteristics of $\mathrm{BeO}$ pellets sintered at 1200 , 1400 and $1600{ }^{\circ} \mathrm{C}$, after irradiation with $1 \mathrm{~Gy}$ beta dose, the pellets were kept in dark at room temperature. The decay of absorbed dose was observed for various storage times up to 1 day. The reduction of integrated OSL outputs, which was obtained at room temperature following $110^{\circ} \mathrm{C}$ for $60 \mathrm{~s}$ preheating for each $200 \mathrm{~s}$ OSL blue light stimulation, as a function of short storage time up to 24 hours was given for all $\mathrm{BeO}$ pellets in Figure 10. Here, we obtained the first readout after half an hour following the radiation exposure. After the $24 \mathrm{~h}$ in which the shallow traps are responsible from the observed fading of the material, the fading of the total OSL signals was found as $-3.1 \%$ and $-4.3 \%$ associated with the 1200 and $1400{ }^{\circ} \mathrm{C}$ sintering temperatures, respectively. There was no fading with respect to the first reading for the samples sintered at $1600^{\circ} \mathrm{C}$.

\section{Conclusion}

The phenomena described in this study show dependence of the $\mathrm{BeO}$ material crystallinity and grain size, and variation of luminescence signal behavior on different sintering temperatures. The work was done on $\mathrm{BeO}$ pellets that were sintered at 1200,1400 and $1600{ }^{\circ} \mathrm{C}$ to report and discuss morphologic and relevant dosimetric, and luminescent properties.

The sintering temperature has a major influence in the TL/OSL intensity and the shape of the TL/OSL curves. It was demonstrated that increasing sintering temperatures creates better crystallinity and higher luminescence intensity at least up to $1600{ }^{\circ} \mathrm{C}$. 
We presented some examples of $\mathrm{TL}$ glow curves obtained on samples of $\mathrm{BeO}$ pellets sintered at 1200,1400 and $1600^{\circ} \mathrm{C}$ after exposure to beta irradiation. The elementary peaks were located at the temperatures 170,275 and $395^{\circ} \mathrm{C} ; 175^{\circ} \mathrm{C}, 275^{\circ} \mathrm{C}$ and $475^{\circ} \mathrm{C}$ and $170{ }^{\circ} \mathrm{C}, \sim 350^{\circ} \mathrm{C}$, $\sim 490{ }^{\circ} \mathrm{C}$ and $\sim 560{ }^{\circ} \mathrm{C}$ for the samples sintered at 1200,1400 and $1600{ }^{\circ} \mathrm{C}$, respectively. The 1200,1400 and $1600^{\circ} \mathrm{C}$-sintered pellet samples of $\mathrm{BeO}$ were activated by $0.1 \mathrm{~Gy}$ exposure of beta radiation and then stimulated with blue-light for $200 \mathrm{~s}$ before TL measurement. We found a de-exciting effect that empties the traps that previously filled by beta radiation by stimulation. We evaluated the bleached TL curve for each sintering temperature. The bleached TL curve (obtained subtracting residual TL glow curve from TL glow curve) and preheating curve of $\mathrm{BeO}$ samples sintered at $1200{ }^{\circ} \mathrm{C}$ showed that the source of the OSL signals is associated with both the $170{ }^{\circ} \mathrm{C}$ and $275{ }^{\circ} \mathrm{C}$ bleached TL peaks and the OSL employs the same recombination centers as the $170{ }^{\circ} \mathrm{C}$ and $275^{\circ} \mathrm{C}$ bleached TL peaks. For the BeO pellets sintered at $1400{ }^{\circ} \mathrm{C}$, we suggested that the origin of the OSL signals might be associated with only the $275^{\circ} \mathrm{C} \mathrm{TL}$ peak. It is not clear that whether the OSL and TL signals occurred from the same trap or not. But, it is also possible that the $275^{\circ} \mathrm{C}$ TL peak is not due to a single trap distribution but an integration of overlapping traps. On the other hand, it is possible to say that even the $175{ }^{\circ} \mathrm{C}$ TL peak did not contribute to the OSL signals and the optically extracted charges from the 175 ${ }^{\circ} \mathrm{C}$ trap may make some non-radiative transitions or the luminescence emission may not be at the transmittance range of the detection filter $(340 \pm 40 \mathrm{~nm})$. For the samples sintered at 1600 ${ }^{\circ} \mathrm{C}$, the source of the OSL signal is associated with the $170{ }^{\circ} \mathrm{C}$ TL peak, and the OSL signals occur from the same recombination centers with the $170^{\circ} \mathrm{C} T \mathrm{~T}$ peak.

We compared the X-ray luminescence spectra of $\mathrm{BeO}$ pellets sintered at three different temperatures at 1200,1400 and $1600^{\circ} \mathrm{C}$. The $\mathrm{XL}$ spectrum of each sample has the same broad peak located between 200 and $450 \mathrm{~nm}$ with peak maximum at $250 \mathrm{~nm}$ (between 6.2 and 2.7 $\mathrm{eV}$ ) with different amplitude from the others

When we used the reading temperature method, the quenching energies were calculated as $0.61,0.55$ and $0.53 \mathrm{eV}$ for the samples sintered at 1200,1400 and $1600{ }^{\circ} \mathrm{C}$, respectively. On the other hand, when the method of TOSL was used, the quenching energies were determined as $0.57,0.54$ and $0.51 \mathrm{eV}$, for the samples sintered at the above temperatures, respectively.

The general characteristics of $\mathrm{BeO}$ pellets sintered at $1600{ }^{\circ} \mathrm{C}$ for use in dosimetry can be summarized as follows: i) Very high sensitivity to beta irradiation with minimum detectable dose 
value of $8 \mu \mathrm{Gy}$ which was calculated using total OSL signal. ii) Wide range of a linear response for beta dose exposures from 0.1 to $50 \mathrm{~Gy}$. iii) The material suffers no radiation damage at 0.2 Gy and total OSL sensitivity was increased only $1 \%$ with respect to the first cycle by repeated exposure and reprocessing. iv). The fading rate for the dosimeters received exposures of $1 \mathrm{~Gy}$ and stored at room temperature in dark was around $3 \%$ in first hour but in the course of $24 \mathrm{~h}$ it gave the same result with the first total OSL intensity value.

\section{References}

Albrecht, H.O., Mandeville, C.E., 1956. Storage of Energy in Beryllium Oxide. Physical Review $101,1250-1252$.

Balian, H.G., Eddy, N.W., 1977. Figure-of-merit (FOM), an improved criterion over the normalized chi-squared test for assessing goodness-of-fit of gamma-ray spectral peaks. Nuclear Instruments and Methods 145, 389-395.

Bøtter-Jensen, L., McKeever, S.W., Wintle, A.G., 2003. Optically stimulated luminescence dosimetry. Elsevier.

Bulur, E., 2007. Photo-transferred luminescence from BeO ceramics. Radiation Measurements 42, 334-340.

Bulur, E., 2014. More on the TR-OSL signal from BeO ceramics. Radiation Measurements 66, 12-20.

Bulur, E., Goksu, H.Y., 1998. OSL from BEO ceramics: New observations from an old material. Radiation Measurements 29, 639-650.

Bulur, E., Saraç, B.E., 2013. Time-resolved OSL studies on BeO ceramics. Radiation Measurements 59, 129-138.

Bulur, E., Yeltik, A., 2010. Optically stimulated luminescence from BeO ceramics: An LM-OSL study. Radiation Measurements 45, 29-34.

Chen, R., McKeever, S.W., 1997. Theory of thermoluminescence and related phenomena. World Scientific.

Crase, K., Gammage, R., 1975. Improvements in the Use of Ceramic BeO for TLD. Health Phys 29, 739-746.

Gammage, R., 1977. Further characteristics important in the operation of ceramic BeO TLD. Oak Ridge National Lab., Tenn.(USA). 
Horowitz, Y.S., 1984. Thermoluminescence and Thermoluminescent Dosimetry, v. 2.

Kiiko, V., 2004. Transparent beryllia ceramics for laser technology and ionizing radiation dosimetry. Refract Ind Ceram+ 45, 266-272.

Kiiko, V., Makurin, Y.N., Dmitriev, I., Sofronov, A., Ivanovskii, A., 2001. Correlation between thermally stimulated luminescence and ceramic properties of beryllium oxide (a Review). Glass Ceram $+58,419-423$.

Kitis, G., Polymeris, G.S., Sfampa, I.K., Prokic, M., Meriç, N., Pagonis, V., 2016. Prompt isothermal decay of thermoluminescence in MgB4O7: $\mathrm{Dy}, \mathrm{Na}$ and LiB4O7: $\mathrm{Cu}$, In dosimeters. Radiation Measurements 84, 15-25.

Kortov, V.S., Milman, I.I., 1996. Luminescence properties of transparent BeO:Li ceramics. Radiat Prot Dosim 65, 355-358.

Kortov, V.S., Milman, I.I., Slesarev, A.I., Kijko, V.S., 1993. New Beo Ceramics for TI Esr Dosimetry. Radiat Prot Dosim 47, 267-270.

McKeever, S., 1985. Thermoluminescence of Solids, Cambridge, Univ. Press Cambridge 32.

McKeever, S.W., Moscovitch, M., Townsend, P.D., 1995. Thermoluminescence dosimetry materials: properties and uses.

Ogorodnikov, I., Kruzhalov, A., 1997. Defect properties of beryllium oxide, Materials Science Forum. Trans Tech Publ, pp. 51-56.

Ogorodnikov, I., Kruzhalov, A., Kuznetsov, A.Y., 1996. Thermoluminescence, Point Defects and Recombination Processes in BeO and LiB305 Single Crystals. Radiat Prot Dosim 65, 109-112.

Rhyner, C.R., Miller, W.G., 1970. Radiation dosimetry by optically-stimulated luminescence of BeO. Health Phys 18, 681-684.

Scarpa, G., 1970. The dosimetric use of beryllium oxide as a thermoluminescent material: A preliminary study. Phys Med Biol 15, 667.

Scarpa, G., Benincasa, G., Ceravolo, L., 1971. Further studies on the dosimetric use of BeO as a thermoluminescent material.

Sommer, M., Freudenberg, R., Henniger, J., 2007. New aspects of a BeO-based optically stimulated luminescence dosimeter. Radiation Measurements 42, 617-620.

Sommer, M., Henniger, J., 2006. Investigation of a BeO-based optically stimulated luminescence dosemeter. Radiat Prot Dosimetry 119, 394-397.

Sommer, M., Jahn, A., Henniger, J., 2008. Beryllium oxide as optically stimulated luminescence dosimeter. Radiation Measurements 43, 353-356. 
Tochilin, E., Goldstein, N., Miller, W., 1969. Beryllium oxide as a thermoluminescent dosimeter. Health Phys 16, 1-7.

Wang, X., Wang, R., Peng, C., Li, T., Liu, B., 2010. Synthesis and sintering of beryllium oxide nanoparticles. Progress in Natural Science: Materials International 20, 81-86.

Wang, X., Wang, R., Peng, C., Li, T., Liu, B., 2011. Growth of BeO nanograins synthesized by polyacrylamide Gel route. Journal of Materials Science \& Technology 27, 147-152.

Watanabe, S., Gundu Rao, T.K., Page, P.S., Bhatt, B.C., 2010. TL, OSL and ESR studies on beryllium oxide. J Lumin 130, 2146-2152.

Yamashita, T., Yasuno, Y., Ikedo, M., 1974. Beryllium oxide doped with lithium or sodium for thermoluminescence dosimetry. Health Phys 27, 201-206.

Yukihara, E.G., 2011. Luminescence properties of BeO optically stimulated luminescence (OSL) detectors. Radiation Measurements 46, 580-587.

Zahedifar, M., Mehrabi, M., Modarres, M., Harooni, S., 2011. Thermoluminescece properties of BeO: Mg nanoparticles produced by sol-gel method. Journal of Nanostructures 1, 199-203. 
Table 1. $\tau_{1,2,3}$ decay times and $b_{1,2,3}$ kinetic orders of BeO pellets

\begin{tabular}{lllllllllll} 
& \multicolumn{3}{c}{$\mathrm{S}_{1}$ (Fast component) } & \multicolumn{2}{c}{$\mathrm{S}_{2}$ (Medium component) } & \multicolumn{2}{c}{$\mathrm{S}_{3}$ (Slow component) } \\
\cline { 2 - 10 } & $\mathrm{I}_{1}$ (count) & $\begin{array}{c}\tau_{1} \text { (s } \\
\text { ) }\end{array}$ & $b_{1}$ (a. u. $)$ & $\mathrm{I}_{2}$ (count) & $\tau_{2}$ (s) & $b_{2}$ (a. u.) & $\mathrm{I}_{3}$ (count) & $\tau_{3}$ (s) & $b_{3}$ (a. u.) \\
\hline $\mathrm{BeO}\left(1200^{\circ} \mathrm{C}\right)$ & $4.2 \mathrm{E}+03$ & $\begin{array}{l}2.0 \\
2\end{array}$ & 1.31 & $3.6 \mathrm{E}+03$ & 6.24 & 1.69 & $2.4 \mathrm{E}+02$ & 32.20 & 1.35 \\
\hline $\mathrm{BeO}\left(1400^{\circ} \mathrm{C}\right)$ & $1.3 \mathrm{E}+05$ & $\begin{array}{l}6.5 \\
7\end{array}$ & 2.05 & $1.3 \mathrm{E}+05$ & $\begin{array}{l}36.4 \\
6\end{array}$ & 1.71 & $6.4 \mathrm{E}+04$ & $\begin{array}{l}233.7 \\
3\end{array}$ & 2.03 \\
\hline $\mathrm{BeO}\left(1600^{\circ} \mathrm{C}\right)$ & $2.6 \mathrm{E}+06$ & $\begin{array}{l}5.7 \\
9\end{array}$ & 2.05 & $7.0 \mathrm{E}+05$ & 26.2 & 2.04 & $3.8 \mathrm{E}+05$ & $\begin{array}{l}460.1 \\
0\end{array}$ & 1.27 \\
\hline
\end{tabular}

Table 2. Thermal quenching parameters, $W$ and $C$ values, of BeO pellets

\begin{tabular}{lllllll} 
& \multicolumn{2}{l}{$\mathrm{BeO}\left(1200^{\circ} \mathrm{C}\right)$} & \multicolumn{2}{l}{$\mathrm{BeO}\left(1400^{\circ} \mathrm{C}\right)$} & \multicolumn{2}{l}{$\mathrm{BeO}\left(1600{ }^{\circ} \mathrm{C}\right)$} \\
\cline { 2 - 7 } & $\mathrm{E}_{\mathrm{Q}}(\mathrm{eV})$ & $\mathrm{C}$ (a.u.) & $\mathrm{E}_{\mathrm{Q}}(\mathrm{eV})$ & $\mathrm{C}$ (a.u.) & $\mathrm{E}_{\mathrm{Q}}(\mathrm{eV})$ & $\mathrm{C}$ (a.u.) \\
\hline Reading Temp & 0.61 & $3 \times 10^{7}$ & 0.55 & $1 \times 10^{7}$ & 0.53 & $2 \times 10^{6}$ \\
\hline TOSL & 0.57 & $8 \times 10^{6}$ & 0.54 & $5 \times 10^{6}$ & 0.51 & $7 \times 10^{5}$ \\
\hline
\end{tabular}




\section{List of Figures}

Figure 1. XRD patterns of $\mathrm{BeO}$ pellets sintered at three different temperatures and reference Pdf Card.

Figure 2. SEM images of $\mathrm{BeO}$ pellets sintered at three different temperatures.

Figure 3. OSL signals with decay components of $\mathrm{BeO}$ pellets sintered at three different temperatures.

Figure 4. Direct TL glow curves and TL curves after OSL measurements, after irradiation with $0.1 \mathrm{~Gy}$. Inset figure: Integrated OSL signals of $\mathrm{BeO}$ pellets as a function of preheating temperatures compared to the TL curve of the material obtained with subtracting $T L$ and $T L$ after OSL curves as a function of readout temperature.

Figure 5. XL spectra of $\mathrm{BeO}$ pellets sintered at three different temperatures, 1200, 1400 and $1600{ }^{\circ} \mathrm{C}$ with a resolution of $1 \mathrm{~nm}$ at room temperature.

Figure 6. Normalized OSL intensities of $0.1 \mathrm{~Gy}$ irradiated and preheated $\left(110^{\circ} \mathrm{C}, 60 \mathrm{~s}\right) \mathrm{BeO}$ pellets at various readout temperatures.

Figure 7. The TOSL curves of $\mathrm{BeO}$ samples as obtained by subtracting the TL curves from the TL curves obtained with optical stimulation. Inset: calculation of the thermal quenching energy using the signal intensities of TOSL curves and OSL signals obtained at various readout temperatures ranging from $50^{\circ} \mathrm{C}$ to $110^{\circ} \mathrm{C}$. for $\mathrm{BeO}$ pellet sintered at a) $1200{ }^{\circ} \mathrm{C}$, b) $1400{ }^{\circ} \mathrm{C}$, and c) $1600^{\circ} \mathrm{C}$.

Figure 8. Dose response curves of BeO pellets for different sintering temperatures. The data were obtained from three BeO pellets sintered at 1200,1400 and $1600{ }^{\circ} \mathrm{C}$. Each data point is the mean value of integrated OSL signals from the samples and the standard deviation of the means is represented by the error bars (not visible for some samples due to the error margin too small).

Figure 9. Reusability features of integrated OSL signals from BeO pellets irradiated with $0.2 \mathrm{~Gy}$ beta dose for different sintering temperatures. The $200 \mathrm{~s}$ blue light stimulation was carried out after preheating at $110^{\circ} \mathrm{C}$ for $60 \mathrm{~s}$. The data points are the mean of the three BeO pellets, and the error bars represent standard deviation. 
Figure 10. Decay of integrated OSL signals as a function of short storage time up to $24 \mathrm{~h}$ from $\mathrm{BeO}$ pellets for different sintering temperatures. The first readouts were recorded after half an hour following the radiation exposure with $1 \mathrm{~Gy}$ beta dose and preheating at $110{ }^{\circ} \mathrm{C}$ for $60 \mathrm{~s}$. The data are the average integrated OSL signals of three BeO pellets, the error bars represent standard deviation. 
Figure 1

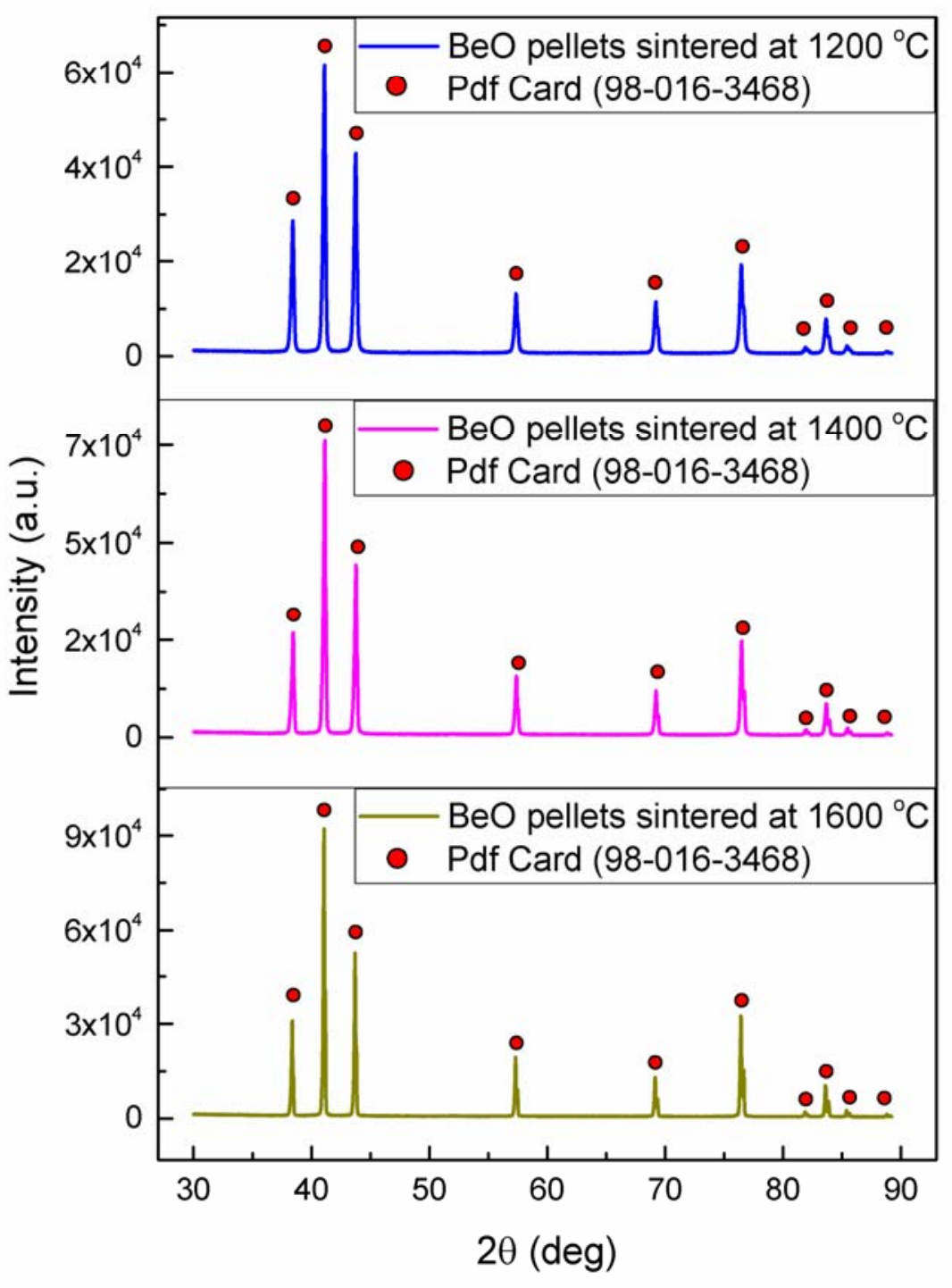


Figure 2

Figure 3
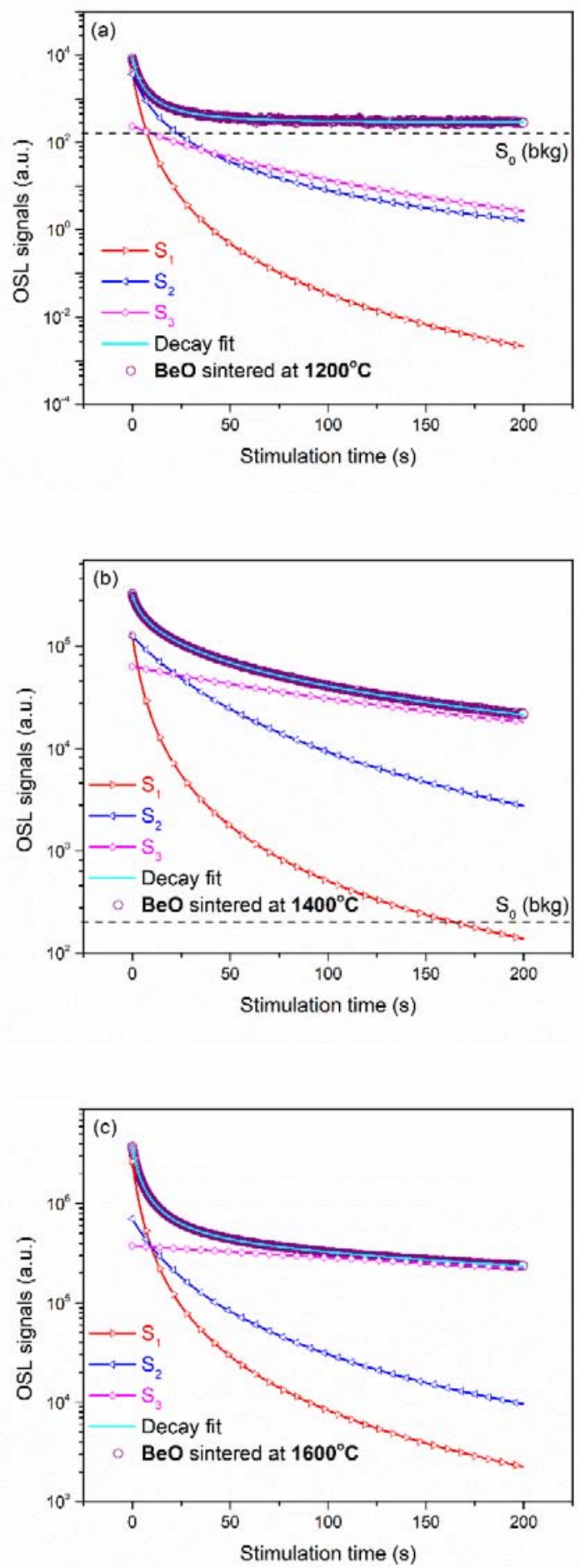
Figure 4
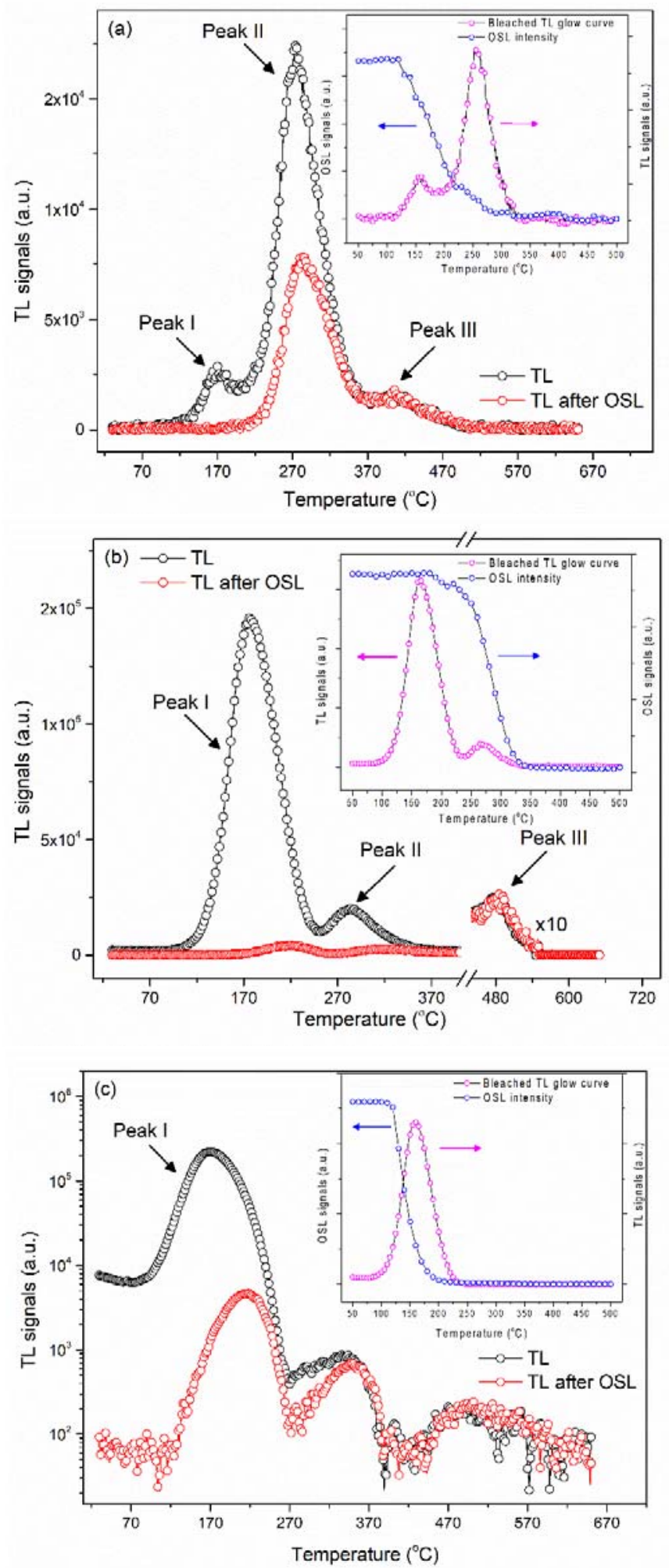


\section{Figure 5}

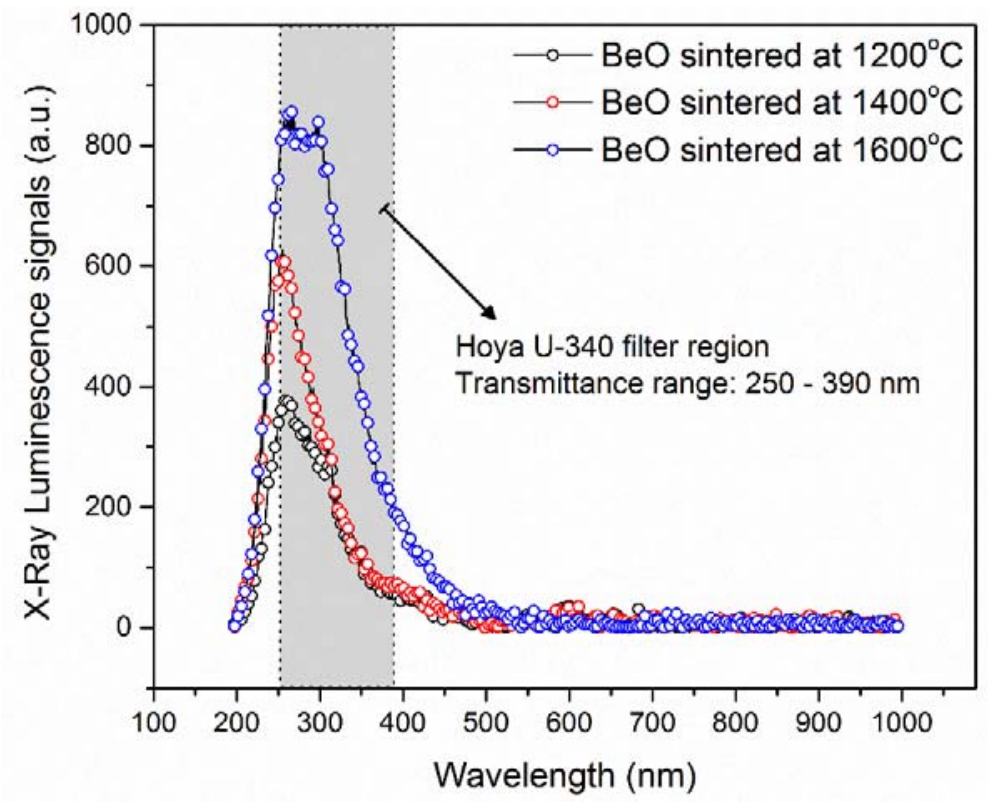


Figure 6




Figure 7



\section{Figure 8}

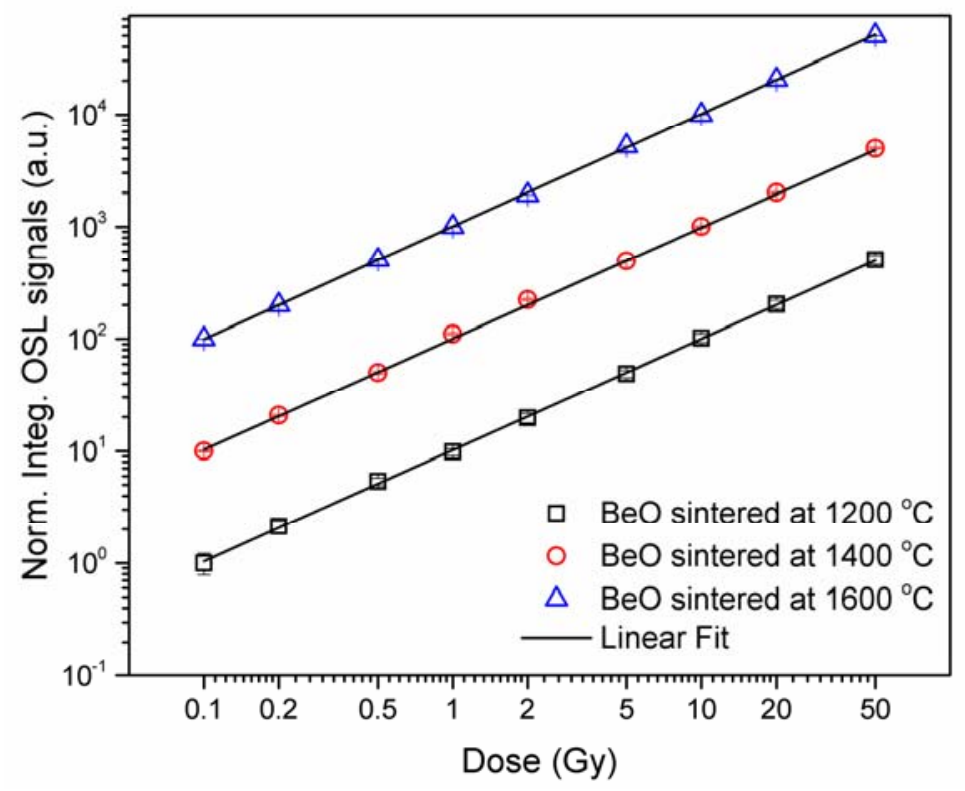


Figure 9

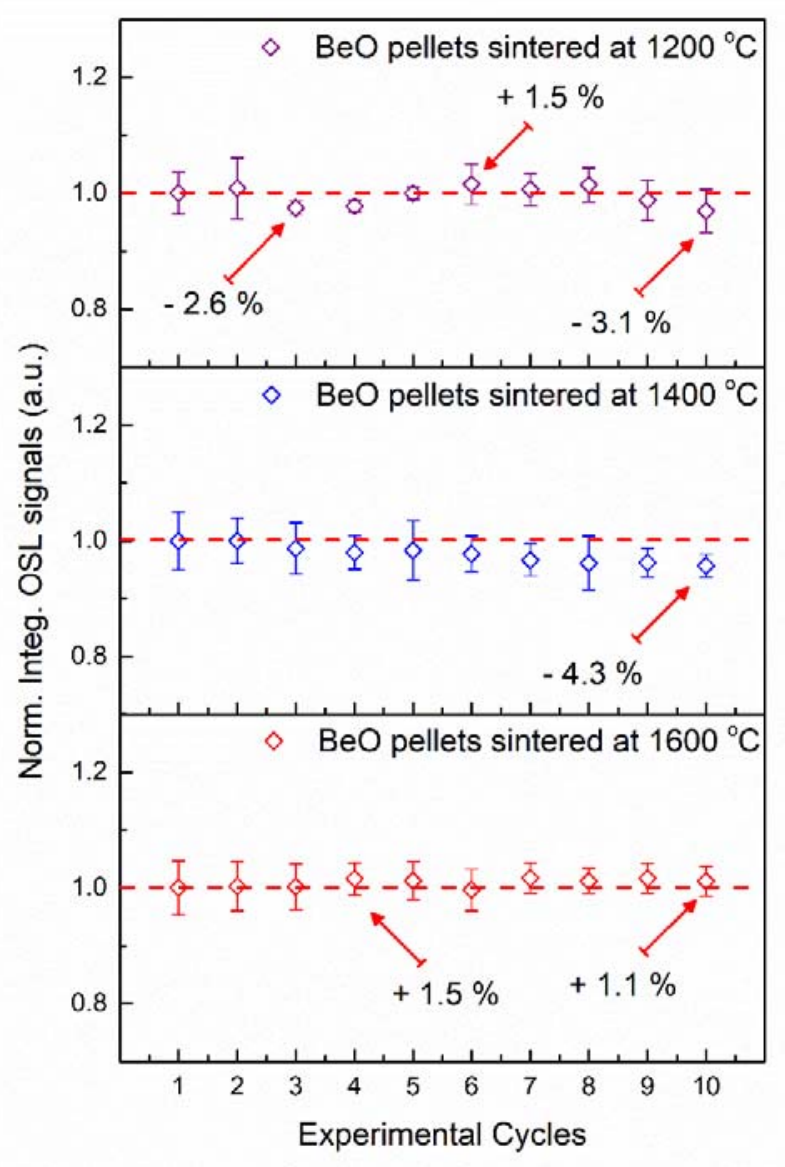


Figure 10



